$\begin{array}{rlr} & \text { diameters, } d / b & {[-]} \\ \eta & = & \text { dimensionless radial distance defined by } \\ & \text { Eq. (A-9) } \\ = & \text { value of } \eta \text { at free surface } \\ \eta_{b} & \text { cylindrical angle } \\ \theta & =\text { viscosity } & {[-]} \\ \mu & = & \text { distance parallel to stream line } \\ \xi & =\text { density } & {[\mathrm{rad} \cdot \mathrm{s}]} \\ \rho & = & \text { stream function defined by Eqs. (3) and }(4) \\ \Psi & {\left[\mathrm{kg} / \mathrm{m}^{3}\right]} \\ \omega & =\end{array}$

1) Baker, A. J.: Int. J. Numerical Meth. Eng., 6, 89 (1973).

2) Connor, J. J. and C. A. Brebbia: "Finite Element Techniques for Fluid Flow," Butterworth, London (1976).

3) Drummond, J.E. and M. I. Tahia: Int. J. Multiphase Flow, 10, 515 (1984).

4) Happel, J.: AIChE J., 5, 174 (1959).

5) Huebner, H.: "The Finite Element Method for Engineers," 2nd ed., Wiley, New York (1982).

6) Pfeffer, R.: Ind. End. Chem. Fundam., 3, 380 (1964).

7) Pfeffer, R. and J. Happel: AlChE J., 10, 605 (1964).

8) Sangani, A. S. and Á. Acrivos: Int. J. Multiphase Flow, 8, 193 (1982).

\title{
EFFECT OF PARTICLE SIZE ON ELUTRIATION RATE CONSTANT FOR A FLUIDIZED BED
}

\author{
KUNIO KATO, SINJI KANBARA, TŌRU TAJIMA, \\ HIDEKI SHIBASAKI, KENJI OZAWA AND TAKAYUKI TAKARADA \\ Department of Chemical Engneering, Gunma University, Kiryu, Gunma 376
}

Key Words: Fluidization, Elutriation Rate, Elutriation Rate Constant, Internal, Particle Size

\begin{abstract}
The elutriation rate constant for the gas-solid fluidized bed with and without vertical multi-tube internals was determined by a continuous steady-state operation. Silica sand, FCC, and glass beads of a wide size distribution were used.

For fine particles belonging to group $A$ of Geldart's classification, the elutriation rate was not affected by bed internals. For coarse particles, however, the rate was affected by the internals.

The elutriation rate constant for the fluidized bed with multitube internals was affected by the gas velocity, terminal velocity of particles, hydraulic diameter of bed and minimum fluidization velocity. Empirical equations for the elutriation rate constant are presented.
\end{abstract}

\section{Introduction}

When particles of a wide size distribution are fluidized, fine particles are carried over from the fluidized bed with the gas stream when the gas velocity exceeds the terminal velocities of the particles.

Many works ${ }^{2,7,12,14,15,19)}$ have been carried out on the elutriation rate from a fluidized bed and many empirical equations have been proposed to estimate the elutriation rate constant.

Figure 1 shows the particle sizes used by previous investigators in Geldart's classification ${ }^{4)}$ map. Many investigators used group B particles. Figure 2 shows the rate constants estimated from the empirical equa-

Received January 9, 1987. Correspondence concerning this article should be addressed to K. Kato. S. Kanbara is now with Idemitsu Petroleun Co., Lid.. Chiba 299-02. T. Tajima is now with Hitachi Chemical Co., Ltd., Simodate 308. K. Ozawa is now with Toshiba Ceramics Co., Ltd., Sinjuku-ku 163. tions published previously. The estimated values are quite different from each other.

Most previous studies were carried out by a batch operation and by using particles of a narrow size distribution.

Since the elutriation rate is affected by the bubble behavior in the bed, the rate may be affected by the average size and size distribution of fluidized particles. It is very important to investigate the elutriation from a fluidized bed by using particles of a wide size distribution under continuous steady-state operation for the design and operation of a commercial plant.

In general, the multitube bundle is immersed in the fluidized-bed reactor to control the bed temperature, but the effect of these tubes upon the elutriation rate is not yet elucidated.

The objective of this study is to obtain more general 


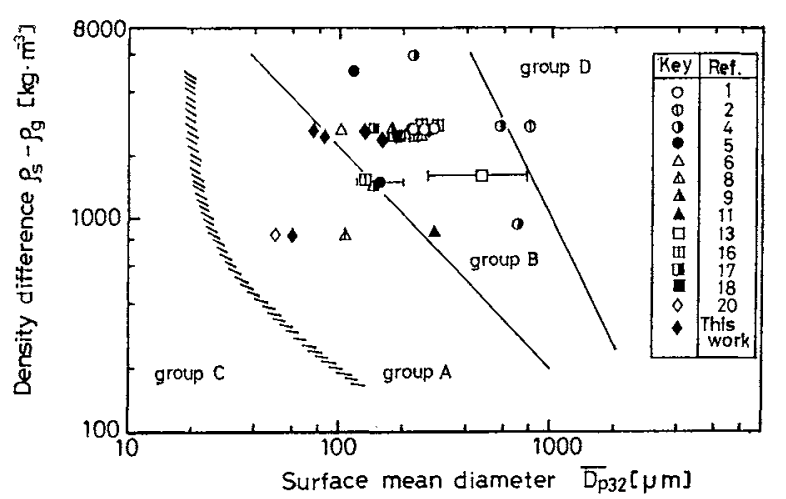

Fig. 1. Fluidized particle size used by previous investigators.

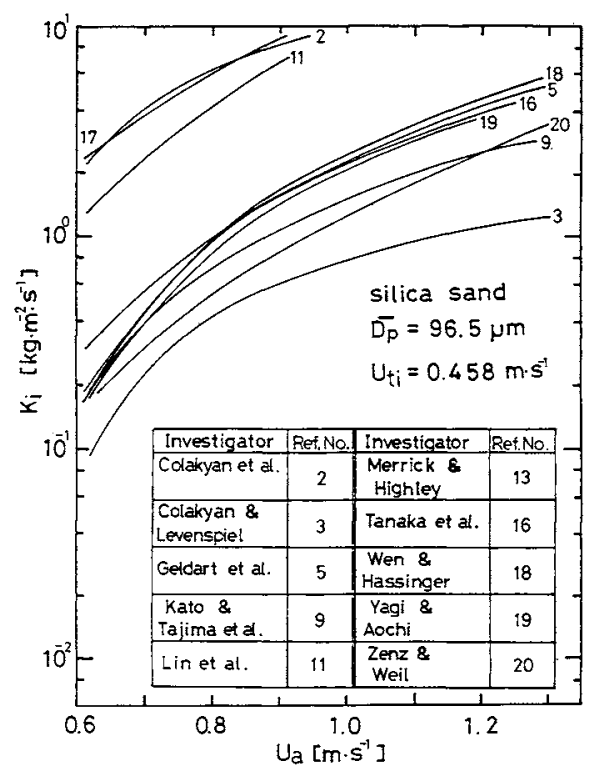

Fig. 2. Estimated value of elutriation rate constant by published correlations.

and quantitative knowledge on the elutriation of particles from a fluidized bed. The elutriation rate constant was determined by using, several kinds of particles of different size distributions in a continuous steady-state operation. The effects of the gas velocity, properties of particles and internals on the elutriation rate constant were investigated. Empirical equations for the elutriation rate constant were obtained.

\section{Experimental Apparatus and Procedure}

Figure 3 shows a schematic diagram of the experimental apparatus. An acrylic resin column of $0.15 \times 0.15 \mathrm{~m}$ rectangular cross section was used as a fluidized bed. The particles elutriated from the bed were separated from gas by cyclones and returned to the dense bed. Tubes made of polyvinyl chloride of 1.8 or $2.6 \mathrm{~cm}$ diameter were immersed vertically in the bed as internals.

After a steady state was established, the elutriated particles was sampled and the weight was measured.
The size distributions of both the elutriated particles and the bed particles were determined by JIS standard sieves.

The hydraulic diameter of the bed, $D_{e}$, is calculated as follows:

$$
D e=\frac{4\left(Z^{2}-n_{i} \pi D_{i}^{2} / 4\right)}{4 Z+n_{i} \pi D_{i}}
$$

Table 1 shows the properties and size distributions of particles used in this experiment. Three kinds of silica sand (fine (SF), middle (SM), coarse (SC)), two kinds of glass beads (fine (GF), coarse (GC)) and FCC particles were used.

According to Geldart's classification the particles used in this work are divided into two groups, A and B. SF, FCC and GF particles belong to the former, whereas SM, SC and GC particles belong to the latter. According to Geldart $^{4)}$ the range of group $A$ is calculated as

$$
U_{m f} \leqq 100 \bar{D}_{p 32}
$$

The surface mean particles diameter, $\bar{D}_{p 32}$, in Table 1 is calculated by the following equation:

$$
\bar{D}_{p 32}=\frac{1}{\sum\left(X_{i} / \bar{D}_{p i}\right)}
$$

In this work, the elutriation rate constant, $K_{i}$, for each component of particles in Table 1 is calculated as follows. It is assumed that the elutriation rate of $i$-component is proportional to the concentration of $i$-component in the bed. ${ }^{10)} K_{i}$ based on unit cross sectional area defined by Wen and Hassinger ${ }^{19)}$ is applied to calculate the rate constant. The following equation is obtained by the material balance of $i$-component at steady state.

$$
\begin{aligned}
F \cdot Y_{i} & =k_{i} \cdot V \cdot C_{i} \\
& =(A / W) K_{i} \cdot V \cdot C_{i} \\
V \cdot C_{i} & =A \cdot L_{f}\left(1-\varepsilon_{f}\right) \rho_{s} \cdot X_{i} \\
& =A \cdot L_{m f}\left(1-\varepsilon_{m f}\right) \rho_{s} \cdot X_{i} \\
& =W \cdot X_{i}
\end{aligned}
$$

From Eqs. (3) and (4)

$$
\begin{aligned}
K_{i} & =\left(F \cdot Y_{i}\right)(W / A)\left(V \cdot C_{i}\right)^{-1} \\
& =(F / A)\left(Y_{i} / X_{i}\right)
\end{aligned}
$$

$K_{i}$ is calculated by measuring the weight of elutriated solids and the size distributions of bed and elutriated solids.

\section{Experimental Results}

Figures 4 and 5 , respectively, show the relation between $K_{i}$ and $U_{a}$ with $\bar{D}_{p}$ and $D_{e}$ as parameters for FCC and SM particles. From these figures, it is found 


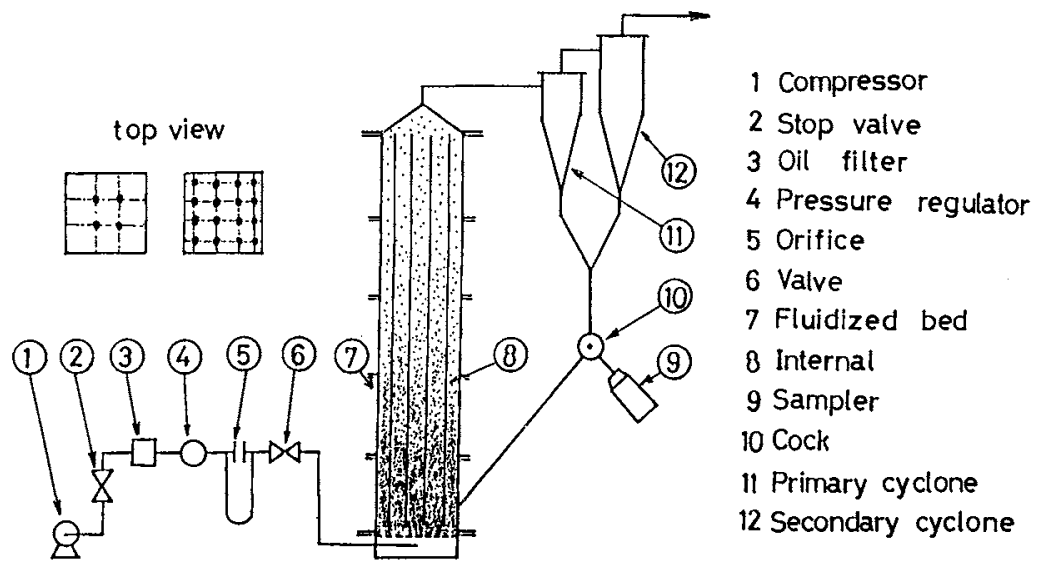

Fig. 3. Experimental apparatus.

Table I. Properties and size distribution of fluidized particles

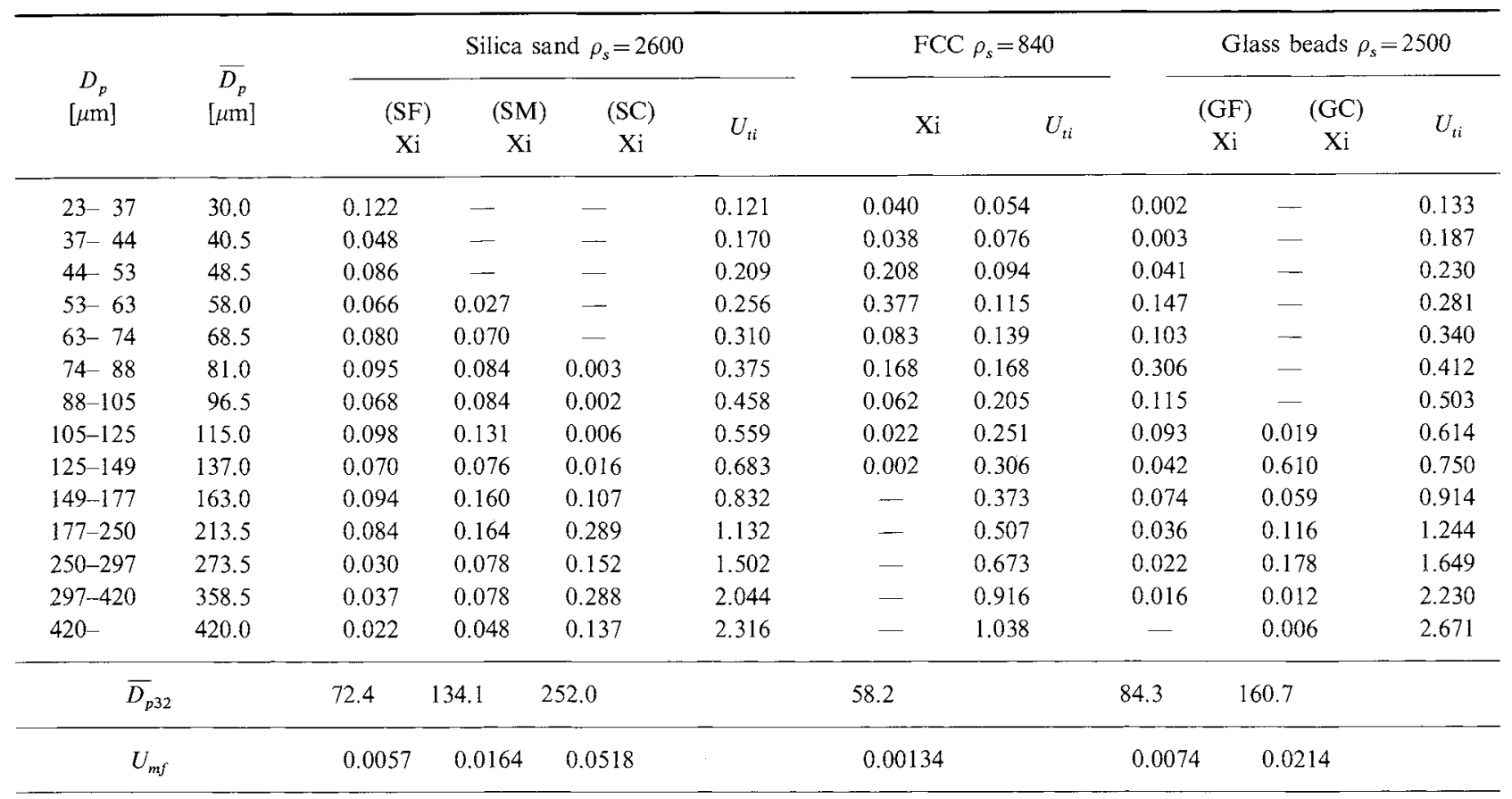

$\rho_{s}$, particle density $\left[\mathrm{kg} / \mathrm{m}^{3}\right] ; U_{i i}$, terminal velocity $[\mathrm{m} / \mathrm{s}] ; U_{m f}$, minimum fluidizing velocity $[\mathrm{m} / \mathrm{s}]$.

that the effect of $D_{e}$ on $K_{i}$ considerably depends on the particle size. When fine particles are fluidized, $K_{i}$ is not affected by $D_{e}$. On the other hand, in the case of the coarse particles, $K_{i}$ increases with decrease of $D_{e}$ at constant gas velocity as shown in Fig. 5.

$K_{i}$ is generally affected by Froude number, $F r$, particle Reynolds number, $R e_{p}$, the minimum fluidizing gas velocity, $U_{m f}, \rho_{s} / \rho_{g}$, and $D_{e}$, where $\mathrm{Fr}$ and $R e_{p}$ are defined as $\left(U_{a}-U_{t i}\right)^{2} / \rho \bar{D}_{p}$ and $\left(\rho_{g} U_{t i} \bar{D}_{p}\right) / \mu$, respectively. Figures $6 \mathrm{a}$ and $\mathrm{b}$ respectively, show the relation between $F r$ and $K_{i} / \rho_{g}\left(U_{a}-U_{t i}\right)$ with $D_{e}$ for $\mathrm{SF}$ and SM particles. The power of $\mathrm{Fr}$ is strongly dependent on $R e_{p}$.

Figure 7 shows the relation between the power of $F r, \alpha$, and $R e_{p}$ of $i$-component particles. The larger $R e_{p}$ is, the smaller $\alpha$ is, and $\alpha$ is proportional to
$\operatorname{Re}_{p}^{-0.4}$.

Figures $8 \mathrm{a}$ and $\mathrm{b}$ show the relation between $K_{i} / \rho_{g}\left(U_{a}-U_{t i}\right)$ and $\operatorname{Re}_{p}$ at $F r^{\alpha}=100 . K_{i} / \rho_{g}\left(U_{a}-U_{t i}\right)$ is proportional to $R e_{p}^{1.6}$ in all kinds of particles used in this experiment.

The effect of $D_{e}$ on the rate constant is shown in Fig. 9. When fine particles are fluidized, $K_{i}$ is not affected by $D_{e}$. However, for coarse particles, $K_{i} / \rho_{g}\left(U_{a}-U_{t i}\right)$ increases with decrease of $D_{e}$ and is proportional to $D_{e}^{-0.52}$.

The effect of $U_{m f}$ on $K_{i}$ is shown in Fig. 10. From this figure, the power of $U_{m f}$ is determined as -0.65 . $K_{i}$ was also affected by $\left(\rho_{s}-\rho_{g}\right) / \rho_{g}$ and $K_{i} / \rho_{g}\left(U_{a}-U_{t i}\right)$ was proportional to $\left\{\left(\rho_{s}-\rho_{g}\right) / \rho_{g}\right\}^{0.61}$. On the other hand, $K_{i}$ for fine particles was hardly affected by $U_{m f}$.

Thus, the following empirical equations are ob- 


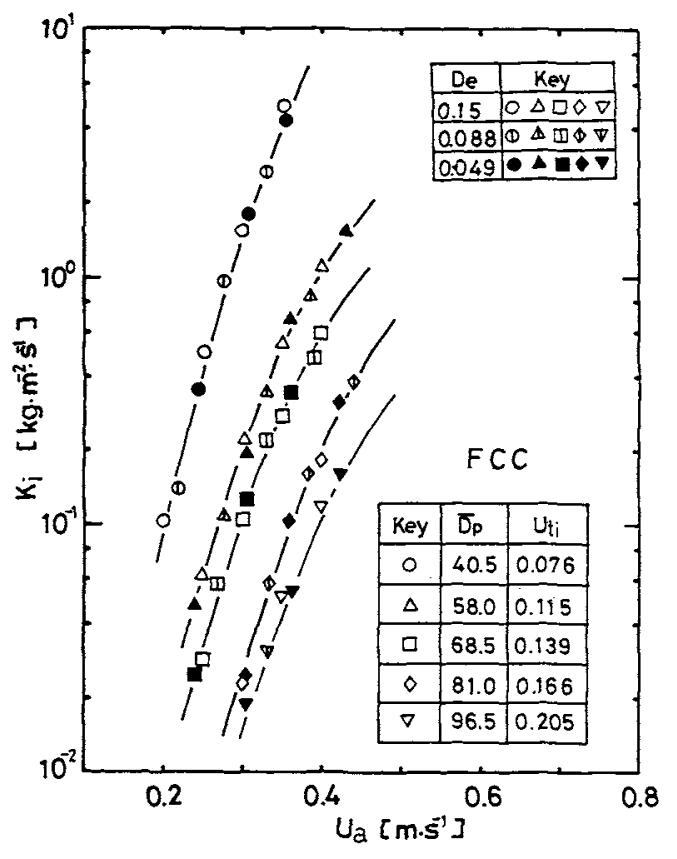

Fig. 4. Relation between $K_{i}$ and $U_{a}$ for F.C.C. particles.

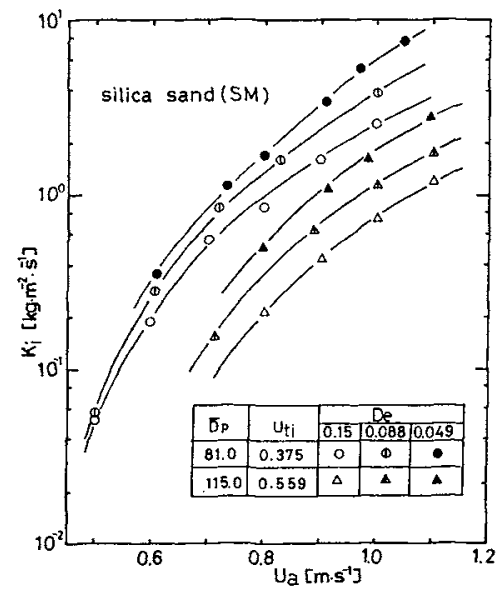

Fig. 5. Relation between $K_{i}$ and $U_{a}$ for silica sand particles (SM). tained for the bed with and without vertical multitube internals.

For the fine particles belonging to the group A:

$$
\begin{gathered}
\frac{K_{i}}{\rho_{g}\left(U_{a}-U_{t i}\right)}=2.07 \times 10^{-4} \mathrm{Fr}^{\alpha} \cdot R e_{p}^{1.6} \cdot\left(\frac{\rho_{s}-\rho_{g}}{\rho_{g}}\right)^{0.61} \\
\left(U_{m f} \leqq 100 \bar{D}_{p 32}, \quad \alpha=R e_{p}^{-0.4}\right)
\end{gathered}
$$

For coarse particles belonging to the group B:

$$
\begin{aligned}
& \frac{K_{i}}{\rho_{g}\left(U_{a}-U_{t i}\right)}=2.65 \times 10^{-6} F r^{\alpha} \cdot R e_{p}^{1.6} \\
& \times D_{e}^{-0.52} \cdot U_{m f}^{-0.65}\left(\frac{\rho_{s}-\rho_{g}}{\rho_{g}}\right)^{0.61} \\
& \left(U_{m f}>100 \bar{D}_{p 32}, \quad \alpha=R e_{p}^{-0.4}\right)
\end{aligned}
$$

Equation (7) does not include the term of $U_{m f}$, since the elutriation rate constant is not affected by $U_{m f}$ when the average particle size is small enough.

Figures 11 and 12 compare the experimental data with calculated values from Eqs. (7) and (8), respectively. All data can be correlated by these equations within $\pm 30 \%$ deviation.

Most previous investigators used group B particles to measure the rate constant as shown in Fig. 1. Therefore, the experimental values of $K_{i}$ for small particles were not well correlated by their equations. Figure 13 compares the estimated values by Eqs. (7) and (8) with the data of the previous investigators. Other experimental data can be correlated by Eqs. (7) and (8) with $\pm 50 \%$ deviation.

\section{Discussion}

The elutriation from a fluidized bed is the ejection of particles from the bed surface due to bursting of bubbles. Thus, the bubble behavior at the bed surface such as bubble diameter and frequency of bubble eruption, affects the elutriation rate. Accordingly, we

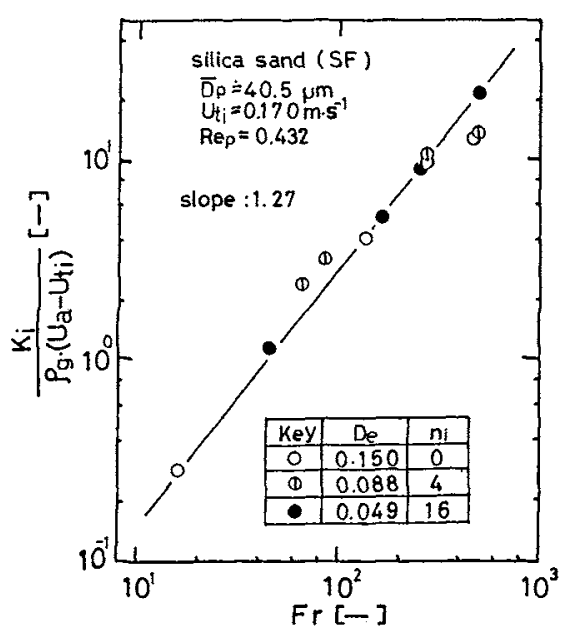

(a)

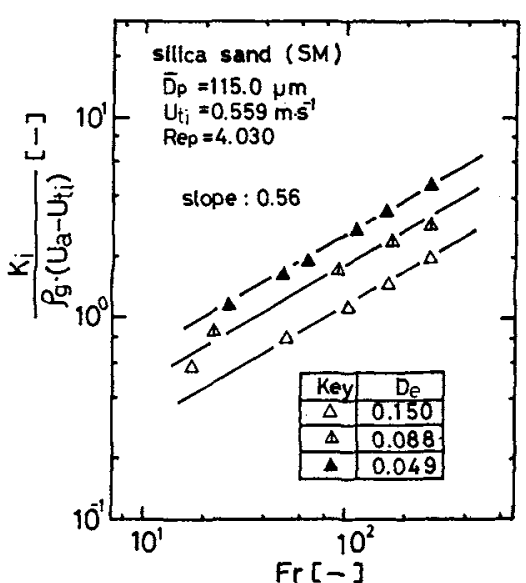

(b)

Fig. 6. Effect of $F r$ number on $K_{i}$ : (a), in the case of SF particles; (b), in the case of SM particles. 


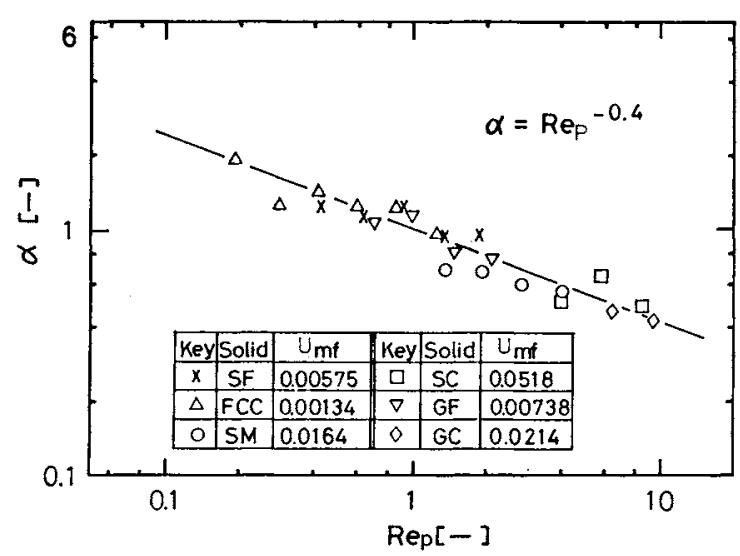

Fig. 7. Relation between $\alpha$ and $R e_{p}$.

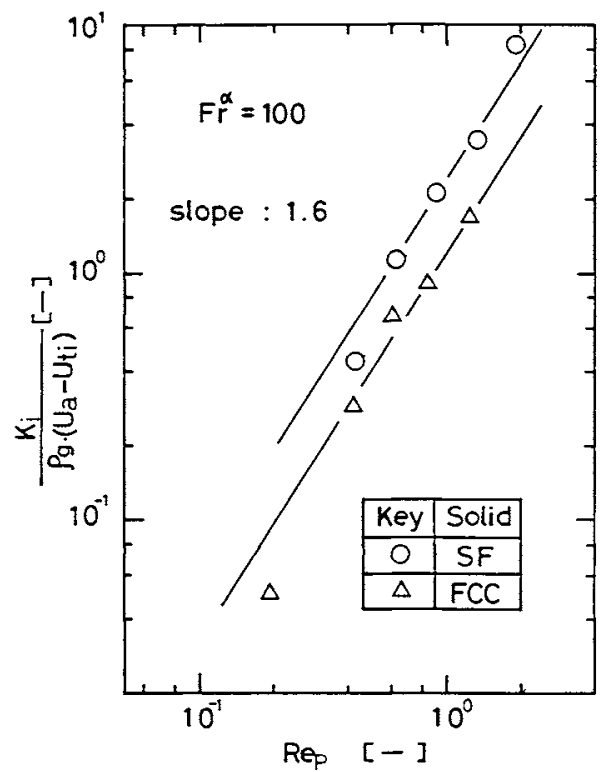

(a)

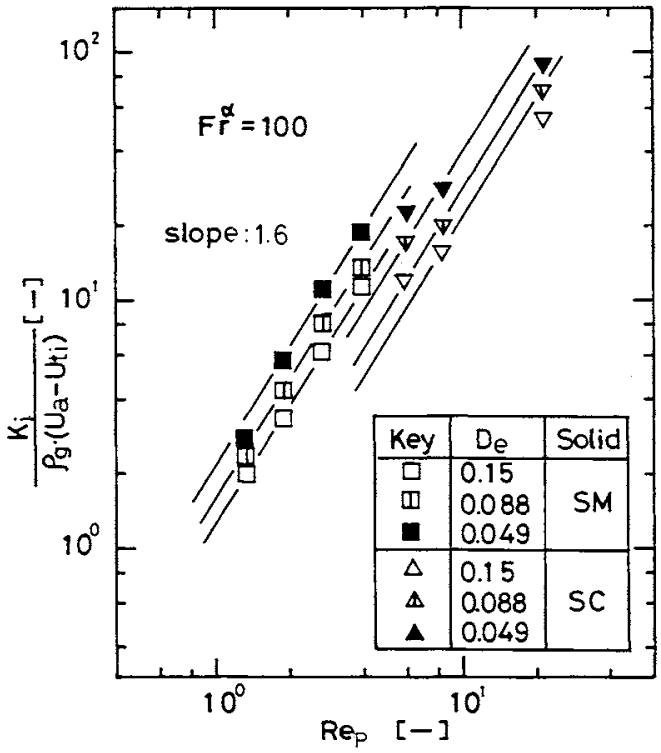

(b)

Fig. 8. Effect of $R e_{p}$ on $K_{i}$. (a), in the case of fine particles; (b), in the case of coarse particles.

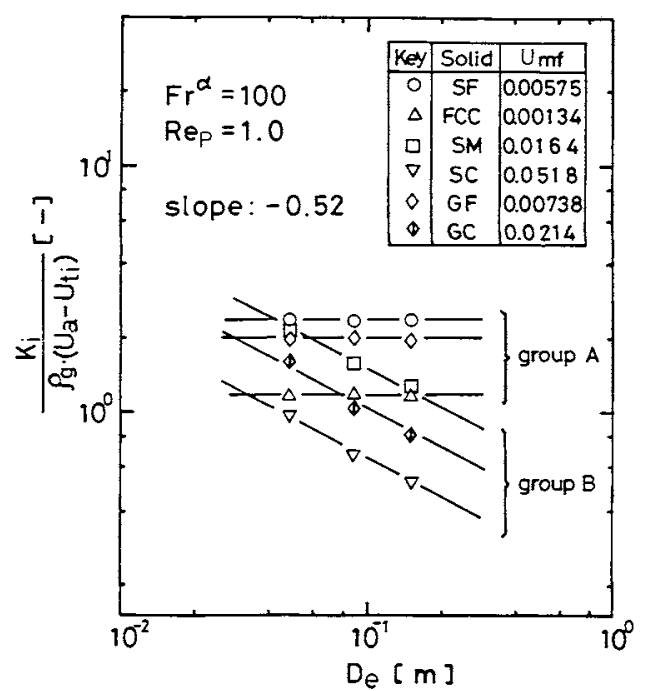

Fig. 9. Effect of $D_{e}$ on $K_{i}$.

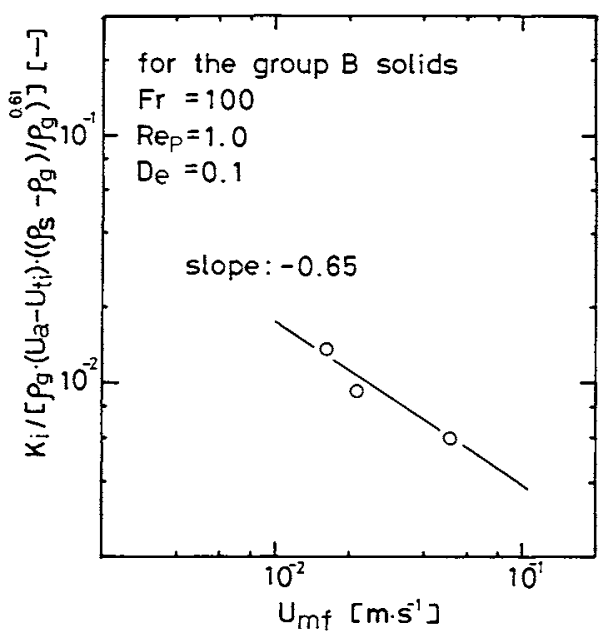

Fig. 10. Effect of $U_{m f}$ on $K_{i}$.

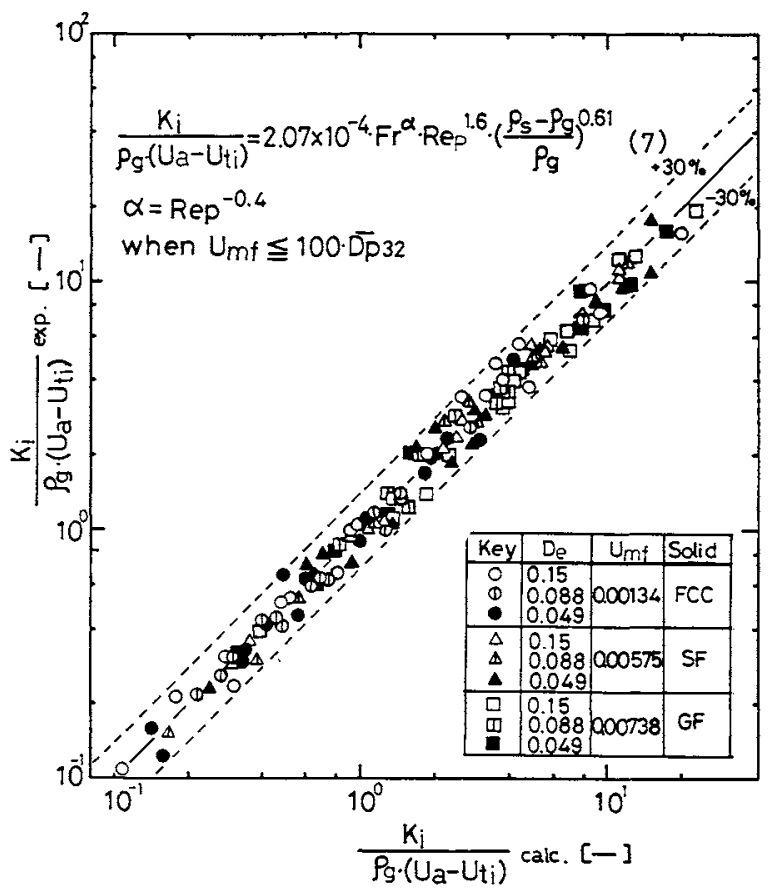

Fig. 11. Comparison of experimental $K_{i}$ with calculated values from Eq. (7) for the group A particles. 


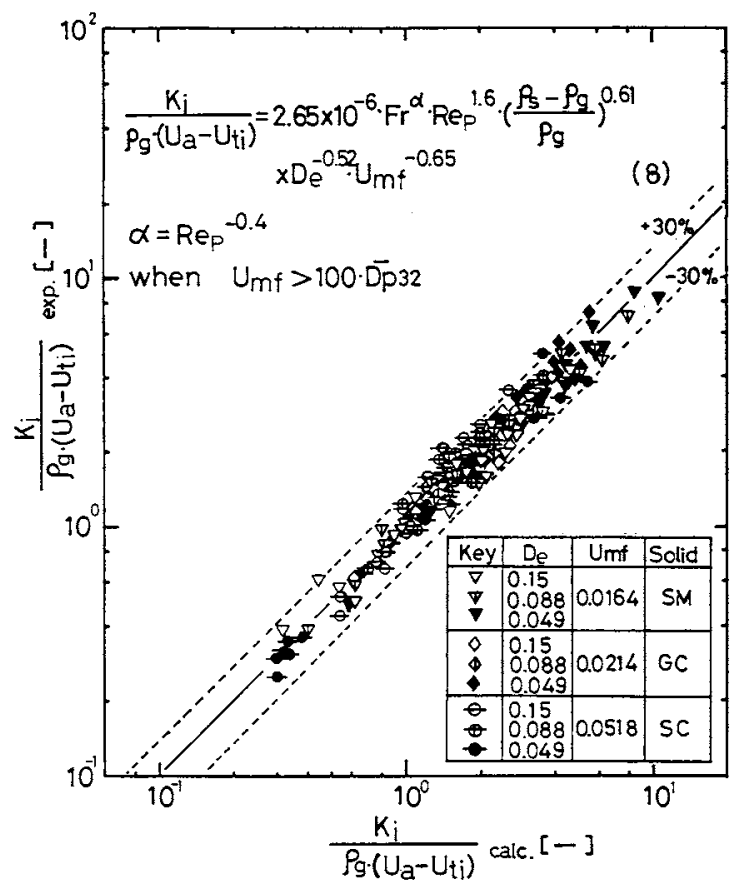

Fig. 12. Comparison of experimental $K_{i}$ with calculated values from Eq. (8) for the group B particles.

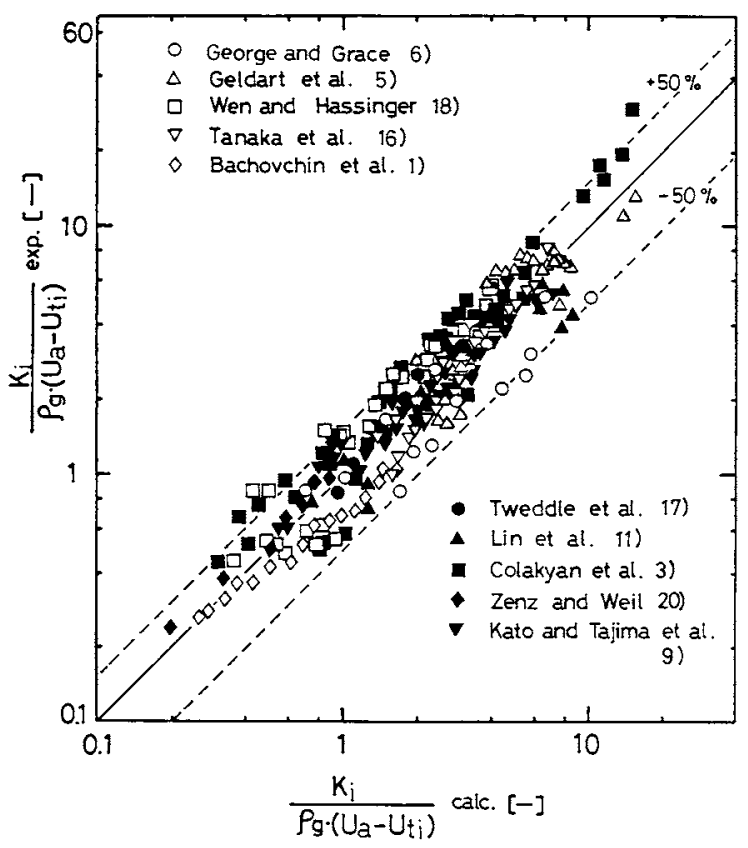

Fig. 13. Comparison of experimental values of other investigators with calculated values by Eqs. (7) and (8).

studied the effect of bubble behavior on the elutriation rate.

In the case of fine particles the fluidization pattern was quite smooth due to a number of small bubbles, and the bubbles do not grow in the bed. Therefore, the average bubble diameter is not affected by the tube internals and the fluidized pattern is not affected by the internals.

On the other hand, in the case of coarse particles the bed is violently fluidized due to large bubbles. When the vertical tube bundle is immersed in the bed of these particles, the bubble diameter is controlled by the tubes and bubble disruption is promoted. Therefore, the bubble frequency in the bed increases.

The effect of $U_{m f}$ on $K_{i}$ has rarely been investigated. Since the elutriation rate is affected by the bubble behavior, the rate may be affected by $U_{m f}$. In this study, it was found that $K_{i}$ is small when the average size of fluidized particles is large. In the case of coarse particles, average bubble size becomes large for large $U_{m f}$. The number of bubbles broken at the bed surface per unit cross section decreases with an increase in $U_{m f}$. Therefore, $K_{i}$ decreases with an increase in $U_{m f}$ at constant gas velocity.

\section{Conclusion}

The elutriation rate of particles from the gas-solid fluidized bed with and without vertical multitube internals was measured under continuous steady-state operation. The following results were obtained.

(1) In the case of fine particles belonging to group A of Geldart's classification, the elutriation rate constant was not affected by the hydraulic diameter of the bed. On the other hand, for coarse particles, the rate constant is strongly affected by the hydraulic diameter, and the rate constant increased with a decrease in the hydraulic diameter.

(2) When coarse particles like group B of Geldart's classification were fluidized, the elutriation rate constant decreased with an increase in the minimum fluidizing gas velocity at constant gas velocity. However, for fine particles, the rate constant was not affected by the minimum fluidizing velocity.

(3) The elutriation rate constant was affected by Froude number, the particle Reynolds number, $\left(\rho_{s}-\rho_{g}\right) / \rho_{g}, U_{m f}$, and the hydraulic diameter. Empirical equations for the elutriation rate constant from the fluidized bed with and without the vertical multitube internals were obtained. The elutriation rate constants from a fluidized bed were well correlated with the empirical equations proposed.

$$
\begin{aligned}
& \text { Nomenclature } \\
& \text { A } \quad=\text { effective cross-sectional area of bed } \quad\left[\mathrm{m}^{2}\right] \\
& C_{i} \quad=\text { concentration of } i \text {-component particles } \\
& \text { in bed } \quad\left[\mathrm{kg} \cdot \mathrm{m}^{-3}\right] \\
& D_{e} \quad=\text { hydraulic diameter } \quad[\mathrm{m}] \\
& D_{i} \quad=\text { tube diameter of internals } \quad[\mathrm{m}]
\end{aligned}
$$

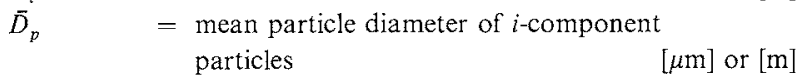

$$
\begin{aligned}
& \bar{D}_{p 32} \quad=\text { surface mean diameter of fluidized particles } \\
& {[\mu \mathrm{m}] \text { or }[\mathrm{m}]} \\
& D_{p} \quad=\text { particle diameter } \quad[\mu \mathrm{m}] \text { or }[\mathrm{m}] \\
& \text { Fr } \quad=\text { Froude number defined by } \\
& \left(U_{a}-U_{t i}\right)^{2} / g \bar{D}_{p} \\
& \begin{array}{lll}
g & =\text { gravitational acceleration } \\
K & =\text { elutriation rate constant based on unit cross- }
\end{array}
\end{aligned}
$$




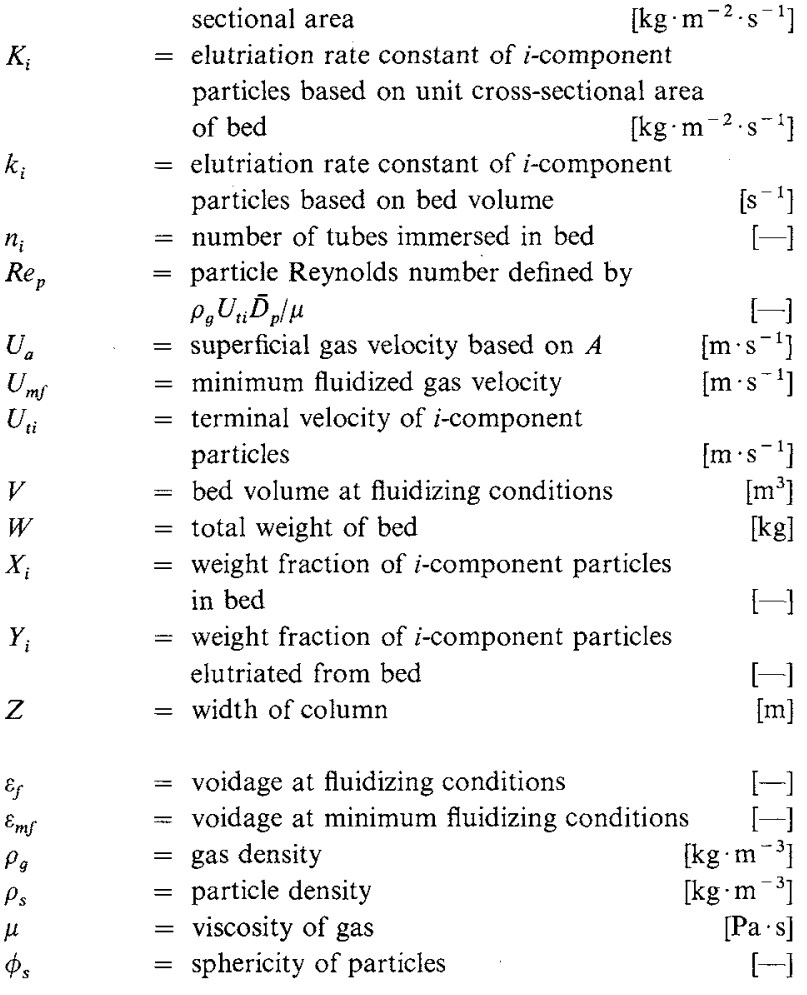

\section{Literature Cited}

1) Bachovchin, D. M., J. M. Beer and A. F. Sarofim: AIChE Symp. Ser, 77, 76 (1981).

2) Colakyan, M., N. Catipovic, G. Jovanovic and T. Fitzgerald:
AIChE Symp. Ser., 77, 205 (1981).

3) Colakyan, M. and O. Levenspiel: Powder Technology, 38, 223 (1984).

4) Geldart, D.: Powder Technology, 7, 285 (1973).

5) Geldart, D., J. Cullinan, S. Georghiades, D. Gilvray and D. J. Pope: Trans. Inst. Chem. Eng., 57, 269 (1979).

6) George, S. E. and J. R. Grace: Can. J. Chem. Eng., 57, 269 (1979).

7) Hatano, H. and M. Ishida: Powder Technology, 35, 201 (1983).

8) Kato, K. and U. Ito: J. Chem. Eng. Japan, 5, 144 (1972).

9) Kato, K., T. Tajima, M. Maa and H. Iwamoto: Conference papers at Second China-Japan Symposium (China), "Fluidization '85," Science Press (1985).

10) Leva, M.: Chem. Eng. Prog., 47, 39 (1951).

11) Lin, L., J. T. Sears and C. Y. Wen: Powder Technology, 27, 105 (1980).

12) Matsuno, Y., H. Kage, T. Nagamitsu et al.: Powder Technology, 33, 65 (1982).

13) Merrick, D. and J. Highley: AIChE Symp. Ser., 70, 366 (1974).

14) Osberg, G. L. and D. H. Charlerworth: Chem. Eng. Prog., 44, 157 (1948).

15) Pemberton, S. T. and J. F. Davidson: "Fluidization," p. 275, Engineering Foundation (1984).

16) Tanaka, I., H. Shinohara, H. Hirosue and Y. Tanaka: $J$. Chem. Eng. Japan, 5, 51 (1972).

17) Tweddle, T. A., C. E. Capes and G. C. Osberg: Ind. Eng. Chem. Proc. Des. Dev., 9, 85 (1970).

18) Wen, C. Y. and R. F. Hassinger: AIChE J., 6, 220 (1960).

19) Yagi, S. and T. Aochi: Paper presented at the Society of Chemical Engineers, Japan, Spring Meeting (1955).

20) Zenz, F. A. and N. A. Weil: AIChE J., 4, 472 (1958). 